\title{
Recovery of patches in an assemblage of geniculate coralline algae: variability at different successional stages
}

\author{
Lisandro Benedetti-Cecchi, Francesco Cinelli
}

Dipartimento di Scienze dell'Ambiente e del Territorio, Università di Pisa, Via A. Volta 6, I-56126 Pisa, Italy

\begin{abstract}
Variability in recovery of cleared patches was investigated for 2 yr (from March 1991 to March 1993) in a low-shore habitat of geniculate coralline algae on the west coast of Italy. A 3-way factorial experiment was used to assess the effects of size, time and location of patch on algal colonization in experimentally cleared plots. Species were grouped in 3 morphological groups: coarsely branched, filamentous and geniculate coralline algae. Cleared plots were small $(7 \times 7 \mathrm{~cm})$, medium $(12 \times 12 \mathrm{~cm})$ and large $(22 \times 22 \mathrm{~cm})$, interspersed in areas of geniculate coralline algae at each of 2 different sites. Replicated clearings and controls were set up in March and September 1991. Seasonal patterns were particularly evident for the filamentous and the geniculate coralline algae, with peaks in abundance occurring in spring and summer for the former group and from September to December for the latter one. Algal colonization was variable in the experimental areas. All main factors (size, time of formation and location of patch) and some of the interactions significantly affected recovery of species, but patterns were specific for each group and were not consistent along the successional sequence. In general, differences due to size and time of formation of patch decreased as succession proceeded, but some exceptions to this trend were also evident. The abundance of coarsely branched algae, for example, was greater in large than in medium gaps after 15 mo of recovery. Differences among sites were particularly evident for the filamentous and coarsely branched algae, but only at determinate successional stages. In addition, temporal trends were not the same for the 2 groups of plants. Spatial patterns were more evident at mid and late successional stages for the former group, whilst the reverse occurred for the latter. Overall, these results suggest caution in contrasting deterministic and nondeterministic views of community dynamics.
\end{abstract}

KEY WORDS: Spatial variability - Temporal variability - Algae - Geniculate corallines - Low-shore habitats $\cdot$ Field experiments $\cdot$ Succession

\section{INTRODUCTION}

The composition and abundance of species in many rocky intertidal and sublittoral communities is highly variable, both in space and time. A major goal of marine ecologists is to describe and to quantify the processes causing such heterogeneity. Many studies have shown that much of this variability is a consequence of the disturbance regime to which communities are exposed and to the modes of recolonisation of the disturbed areas (Dayton 1971, Sousa 1979, 1984, 1985, Paine \& Levin 1981, Dayton et al. 1984, 1992, Dethier 1984, Pickett \& White 1985, Farrell 1989). Physical and biological perturbations produce discrete patches of open space varying in attributes such as age, size and shape. Species with particular life histories may colonize some areas but not others. As the specific composition of a patch varies, the nature and the outcome of the biological processes occurring therein may also vary. For example, organisms that disperse their offspring over long distances may colonize small isolated patches more efficiently than do species with limited dispersive ability, the latter becoming more abundant in large clearings (Kay \& Keough 1981, Keough 1984, Sousa 1984, Butler 1991). Some experimental evidence suggests that dispersive ability may be negatively correlated with competitive ability in assemblages of sessile invertebrates (Keough 
1984, Butler 1991). In these circumstances competitive exclusion may occur more frequently in large patches than in small areas, the latter serving as refuges or windows of opportunity for species that are good recruiters, but not good competitors

In algal assemblages, the size of patches may affect recruitment of species more indirectly by influencing the abundance of herbivores. Sousa (1984) demonstrated experimentally that small gaps supported higher densities of limpets than did large ones. As a consequence of the distribution of the herbivores, small gaps were colonized mainly by grazer-resistant algae, while vulnerable plants became more abundant in large patches. When limpets were excluded, however, such patterns were no longer evident and the same algal assemblage developed in areas of different size.

Although the examples illustrated above are consistent with a non-deterministic view of community dynamics, generalizatıons are not possibie and sume contrasting evidence is also available. For example, some authors have found that clearings produced in different periods of the year support distinct early successional algai assemblages because of the seasonality of reproduction and growth of species (Foster 1975, Sousa 1979, 1985, Hawkins 1981, Turner 1983a, Breitburg 1985). Such areas would be expected to become dominated by different organisms, since initial variability might influence the recruitment of later colonists (e.g. Turner 1983b, Farrell 1991). Studies from rocky intertidal communities indicated, however, that differences among gaps of different sizes became less evident as colonisation proceeded. The same species characterized the final stages of the successional sequence (Sousa 1985 and references therein).

Despite the theoretical and empirical relevance of the above considerations, few studies have specifically investigated whether the variability in recovery of patches exhibited by some early successional assemblages is consistent through time or not (but see Wootton 1993). Probably, this is a consequence of the long time necessary for many natural patches to reach the end-point of the successional sequence (which is often longer than that available for ecological investigations; see Likens 1992). In this respect, the assemblages of geniculate coralline algae occurring in shallow habitats in the western Mediterranean might provide a useful experimental system. Such assemblages are, in fact, dominated by fast-growing organisms which may regenerate from their persistent basal crusts after a disturbance (Littler \& Kauker 1984, Konar \& Foster 1992). Moreover, most of the associated species are filamentous algae with great reproductive output and dispersive ability (Santelices 1990). These life histories suggest that assemblages dominated by geniculate coralline algae recover quickly after a perturbation, thus representing a suitable system for relatively shortterm studies on recolonisation of patches.

Here, we present the results of a 2 yr investigation carried out in a low-shore habitat of geniculate coralline algae on the rocky coast south of Livorno, Italy. This study was designed to address the following questions. (1) Are there differences in recovery of patches among areas of different size, produced in different periods of the year and located at different sites? (2) Do these variables interact significantly to produce additional variability in recovery of patches? (3) If there are differences among treatments, are they consistent along the successional sequence? A 3-way factorial experiment was designed to answer these questions. In regard to the last one, 3 sampling dates representing different successional stages were analysed for each dependent variable (algal morphological groups).

\section{METHODS}

Study sites and organisms. This study was done from 1991 to 1993 on the rocky coast south of Livorno, Italy $\left(43^{\circ} 30^{\prime} \mathrm{N}, 10^{\circ} 20^{\prime} \mathrm{E}\right)$. The experimental plots were interspersed on sandstone platforms located from 0 to $-0.5 \mathrm{~m}$ below Mean Low Level Water. Manipulations were replicated at 2 sites (Site A: Boccale; Site B: Piscine) which provided 2 different habitat types. These sites, although close to each other (about $1 \mathrm{~km}$ apart) were dominated by different organisms. The sublittoral fringe-habitat at Site A was dominated by the mussel Mytilus galloprovincialis Lamarck and by the brown alga Cystoseira compressa (Esper) Gerloff \& Nizzamuddin. Patches of geniculate corallines were restricted to small areas (about 3 to $5 \mathrm{~m}^{2}$ ) among those occupied by the mussels and $C$. compressa. The opposite situation occurred at Site $B$, where much of the substratum was dominated by mats of articulated corallines. This study deals with the patterns of algal recovery in these patches, while the Mytilus-Cystoseira assemblage is still under investigation

At both sites, the most representative calcified algae were Corallina elongata Ellis \& Solander and Haliptilon virgatum (Zanardini) Garbary \& Johansen which formed dense mats about 3 to $5 \mathrm{~cm}$ high. Other plants living in these mats were filamentous species (mainly Polysiphonia spp.) and the coarsely branched algae Chondria boryana (De Notaris) De Toni, Gastroclonium clavatum (Roth) Ardissone and Laurencia obtusa (Hudson) Lamouroux. Small samples of algae were collected several times from the study areas and analyzed in the laboratory. These analyses revealed no differences in species composition among sites.

Although much of the surface of the rocks in the assemblage of geniculate coralline algae was occupied 
by erect plants, patches of open space produced by natural disturbances were also present. The areal extent of such gaps ranged from 5 to $500 \mathrm{~cm}^{2}$, with the size-frequency distribution skewed towards the small patches (Benedetti-Cecchi unpubl. data).

Herbivores were uncommon in the experimental areas. Sea urchins, although abundant in nearby littoral pools, were never seen in the sublittoral fringe throughout the study period. Limpets (Patella aspera Roeding and $P$. coerulea L.) were found occasionally in patches of bare rock or occupied by the encrusting base of Corallina elongata. Further descriptions of the study area can be found elsewhere (Benedetti-Cecchi 1993).

Experimental design, collection and analysis of data. A 3-way factorial experiment was designed to study the spatial and temporal patterns of algal recovery in artificially cleared plots. At each site, the experimental units were stratified in patches of articulated corallines and were prepared by clearing the substratum with a paint scraper and a plastic brush. The corners of each plot were marked with small pieces of epoxy putty (Subcoat S). Scraping, like natural disturbance, allowed the removal of erect macroalgae while encrusting organisms remained attached to the rock. Treatments were: (1) site (Boccale vs Piscine); (2) size $(7 \times 7,12 \times 12$ and $22 \times 22 \mathrm{~cm}$ plots $)$; and (3) time of formation (March vs September). Eighteen experimental units were randomly distributed in each site at the beginning of the study (March 1991). Treatments were assigned to these units at random and were replicated 3 times. Moreover, 3 additional plots were also marked at each site in order to monitor seasonal fluctuations of algal abundance in unmanipulated areas.

The abundance of macroalgae was determined at 2 or 3 monthly intervals from March 1991 to March 1993. Plexiglass sheets of the same size as the experimental plots were used to evaluate the percent cover of the following algal morphological groups (see also Littler \& Littler 1980 and Steneck \& Watling 1982): coarsely branched algae, filamentous algae and geniculate corallines. A surface of $25 \mathrm{~cm}^{2}$ was sampled in the centre of the small plots $(7 \times 7 \mathrm{~cm})$ using a sheet with 25 equally spaced dots. Percent cover values were assessed by counting the number of dots lying over each algal group. The same technique was used to sample the medium $(12 \times 12 \mathrm{~cm})$, the large $(22 \times 22 \mathrm{~cm})$ and the control $(12 \times 12 \mathrm{~cm})$ quadrats. In these cases, a $100 \mathrm{~cm}^{2}$ surface was sampled in the middle of each plot using plexiglass sheets with 100 equally spaced dots.

Data were analysed using 3 -way mixed model ANOVAs. Site was treated as a random factor, while size and time were considered fixed. Data from small plots were not included in the ANOVAs because of differences in sampling areas. In this case the effects of treatments were deduced from inspection of graphs. Percent cover values were arcsine transformed prior to analysis. Cochran's test was performed to check for homogeneity of variances (Winer 1971, Underwood 1981). Plots of residuals were examined after each ANOVA to check if error terms were normally distributed.

In general, tests were done for patches 6, 12 and 18 mo old. The only exception was represented by the coarsely branched algae, for which the last analysis was done after 15 mo from start because of strong heteroscedasticity. These sampling dates, although arbitrarily chosen, represented different successional stages on the basis of the relative abundance of each algal morphological group (see 'Results').

\section{RESULTS}

\section{Unmanipulated plots}

Filamentous algae and geniculate corallines represented the most conspicuous morphological groups of the assemblage. Both showed marked seasonal trends, but patterns in time appeared negatively correlated (Fig. 1). Peaks in abundance occurred in spring and summer for the filamentous species, while the articulated corallines exhibited their maximal cover from September to December. These patterns were consistent at both sites (Fig. 1). In contrast, the coarsely branched algae were not abundant in control plots. A slight seasonal trend was, however, also evident for these species, greater covers occurring in March at both sites (Fig. 1).

\section{Experimental plots}

Total cover values could not be analysed because of heteroscedasticity. Inspection of graphs, however, revealed an important effect of size of patch early in succession (Fig. 2). Large areas supported greater covers of algae than medium and small quadrats. Differences due to size of patch, however, disappeared as colonisation proceeded (Fig. 2). Late in succession (particularly from June to December 1992), algal cover was greater in the small plots cleared in September than in those scraped in March at Site A, while the opposite trend was evident at Site B. Overall, the total cover of macroalgae did not differ considerably between the 2 sites.

To save space, only data illustrating the effects of treatments after 18 mo of recovery (data from 15 mo old patches were used for the coarsely branched algae) are presented in full (Table 1). Filamentous algae were 
Site A

Filamentous algae
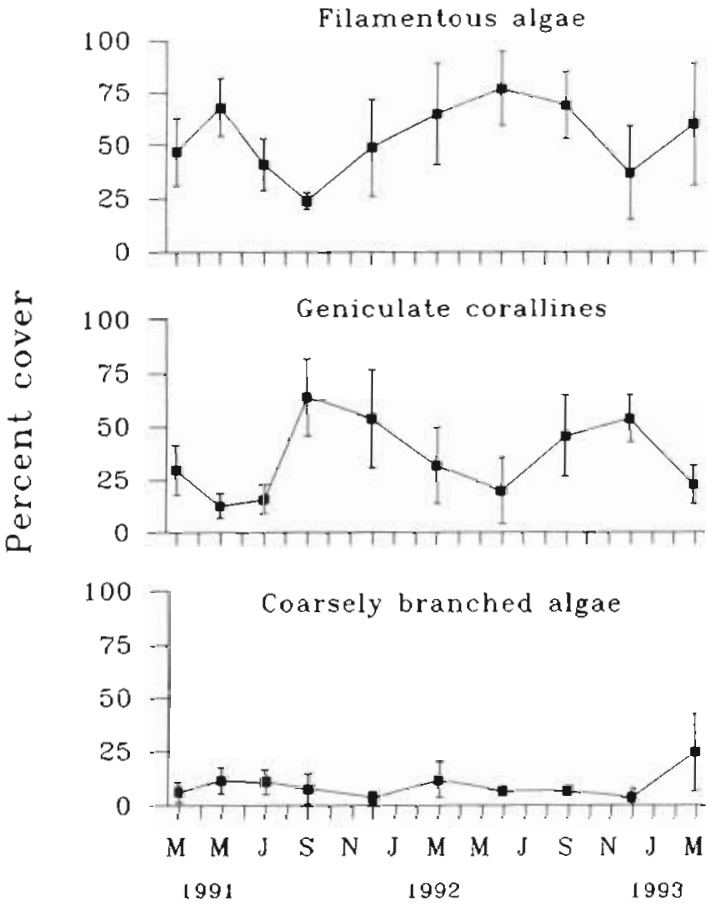

Site $B$

Filamentous algae

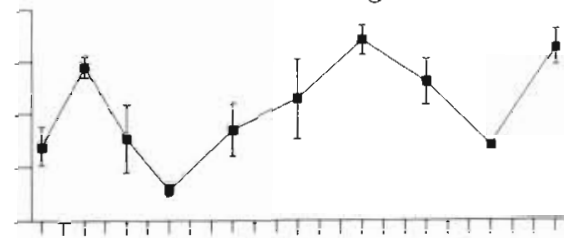

Geniculate corallines

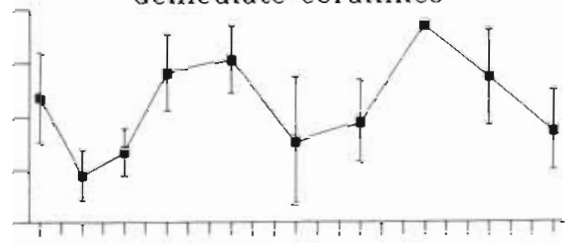

Coarsely branched algae

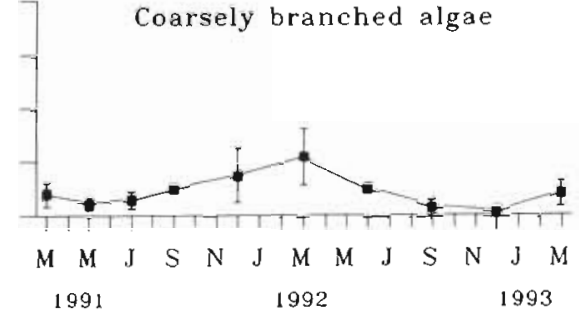

Fig. 1. Mean $( \pm S E$ ) percent covers (untransformed, $n=3$ ) of algal morphological groups in unmanipulated plots near Livorno, Italy, during the course of the study

Site A



0
0
0
0
$\Xi$
0
0
0
0
0

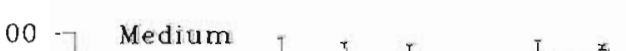

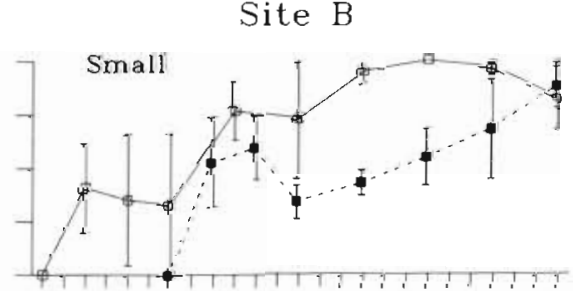
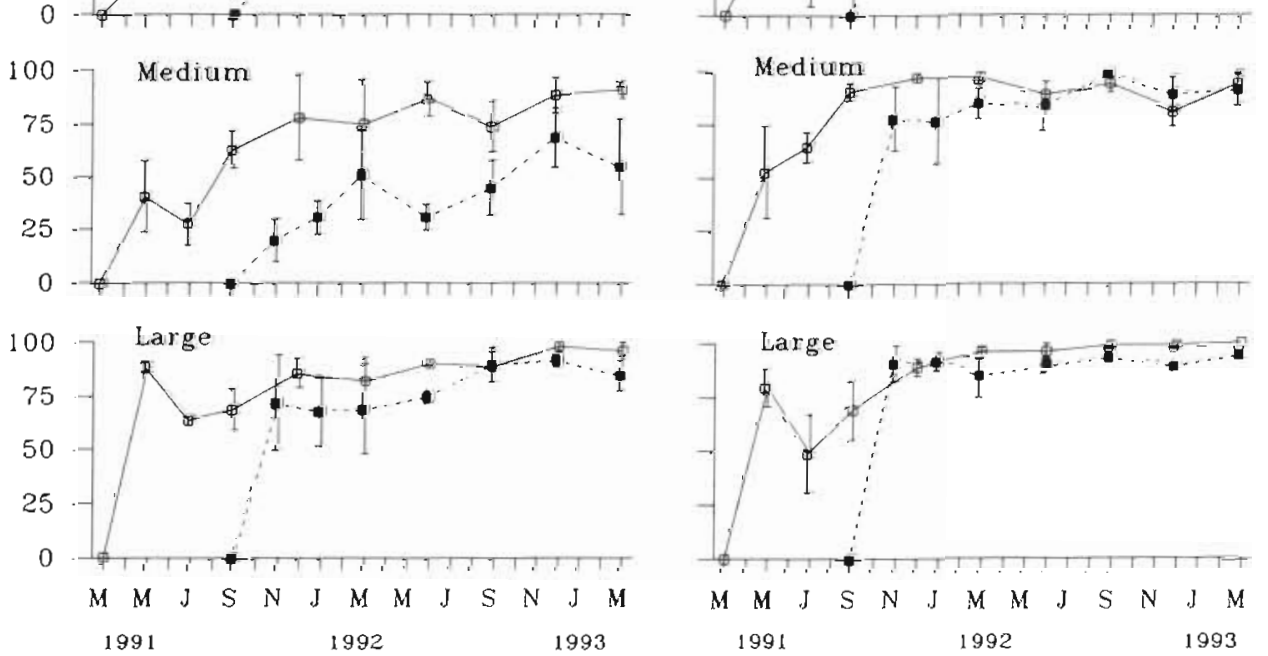

Fig. 2. Effects of size, time of formation and location of patch on total algal cover. Values are mean $( \pm S E, n=3)$ untransformed percent covers. (ㅁ) Plots cleared in March 1991; ( $\mathbf{(})$ plots cleared in September 1991 
Table 1. Analyses of treatment effects on filamentous, geniculate coralline and coarsely branched algae (the data were angular transformed). Data were from 18 mo old patches, except for the coarsely branched algae for which data from 15 mo old gaps were used. Small patches $(5 \times 5 \mathrm{~cm})$ were not included in these tests. Variances were homogeneous $\left(C_{\mathrm{cnt}}=0.51\right)$. Site was treated as a random factor while size and time were fixed. ns: not significant, $p<0.05, \cdots p<0.01$

\begin{tabular}{|c|c|c|c|c|c|c|c|c|c|c|}
\hline \multirow{3}{*}{$\begin{array}{l}\text { Source of } \\
\text { variation }\end{array}$} & \multirow[t]{3}{*}{ df } & \multicolumn{9}{|c|}{ Algal groups } \\
\hline & & \multicolumn{3}{|c|}{ Filamentous algae } & \multicolumn{3}{|c|}{ Geniculate corallines } & \multicolumn{3}{|c|}{$\begin{array}{c}\text { Coarsely branched } \\
\text { algae }\end{array}$} \\
\hline & & MS & $F$ & $\mathrm{p}$ & MS & $F$ & $\mathrm{p}$ & MS & $F$ & $\mathrm{p}$ \\
\hline Site & 1 & 0.674 & 8.32 & - & 0.141 & 2.71 & ns & 0.121 & 2.69 & ns \\
\hline Size & 1 & 0.075 & 0.39 & ns & 0.000 & 0.01 & ns & 0.075 & 2289.38 & $\cdot$ \\
\hline Time & 1 & 0.428 & 0.59 & ns & 0.939 & 781.31 & $\cdot$ & 0.631 & 42687.64 & $\cdots$ \\
\hline Site $\times$ Size & 1 & 0.193 & 2.38 & ns & 0.013 & 0.25 & ns & 0.000 & 0.00 & ns \\
\hline Site $\times$ Time & 1 & 0.816 & 10.07 & $\cdots$ & 0.000 & 0.02 & ns & 0.000 & 0.00 & ns \\
\hline Size $\times$ Time & 1 & 0.002 & 0.01 & ns & 0.014 & 4.67 & ns & 0.022 & 1.57 & ns \\
\hline Site $\times$ Size $\times$ Time & 1 & 0.205 & 2.53 & ns & 0.003 & 0.06 & ns & 0.014 & 0.31 & ns \\
\hline Error & 16 & 0.081 & & & 0.058 & & & 0.045 & & \\
\hline Cochran's test: & & & $C=0.27$ & & & $C=0.27$ & & & $C=0.30$ & \\
\hline
\end{tabular}

the most abundant species in the experimental plots during the early stages of succession (Fig. 3). Patterns of colonisation were, however, highly variable among treatments. For example, although the quadrats cleared in March and those cleared in September became occupied by the filamentous algae, their abundance declined sharply in the former, but not in the latter (Fig. 3). Late in succession, however, differences attributable to the season at which the experiment started were less evident and the successional trajectories observed at each site converged towards similar points (Fig. 3). Size of patch affected the abundance of filamentous algae in the experimental areas, the large gaps supporting higher covers of these species. The pattern was, however, variable along the successional sequence. Differences were evident for 2 mo old areas (Fig. 3, graphical comparisons) but they were not significant after 6,12 and 18 mo from the start of the
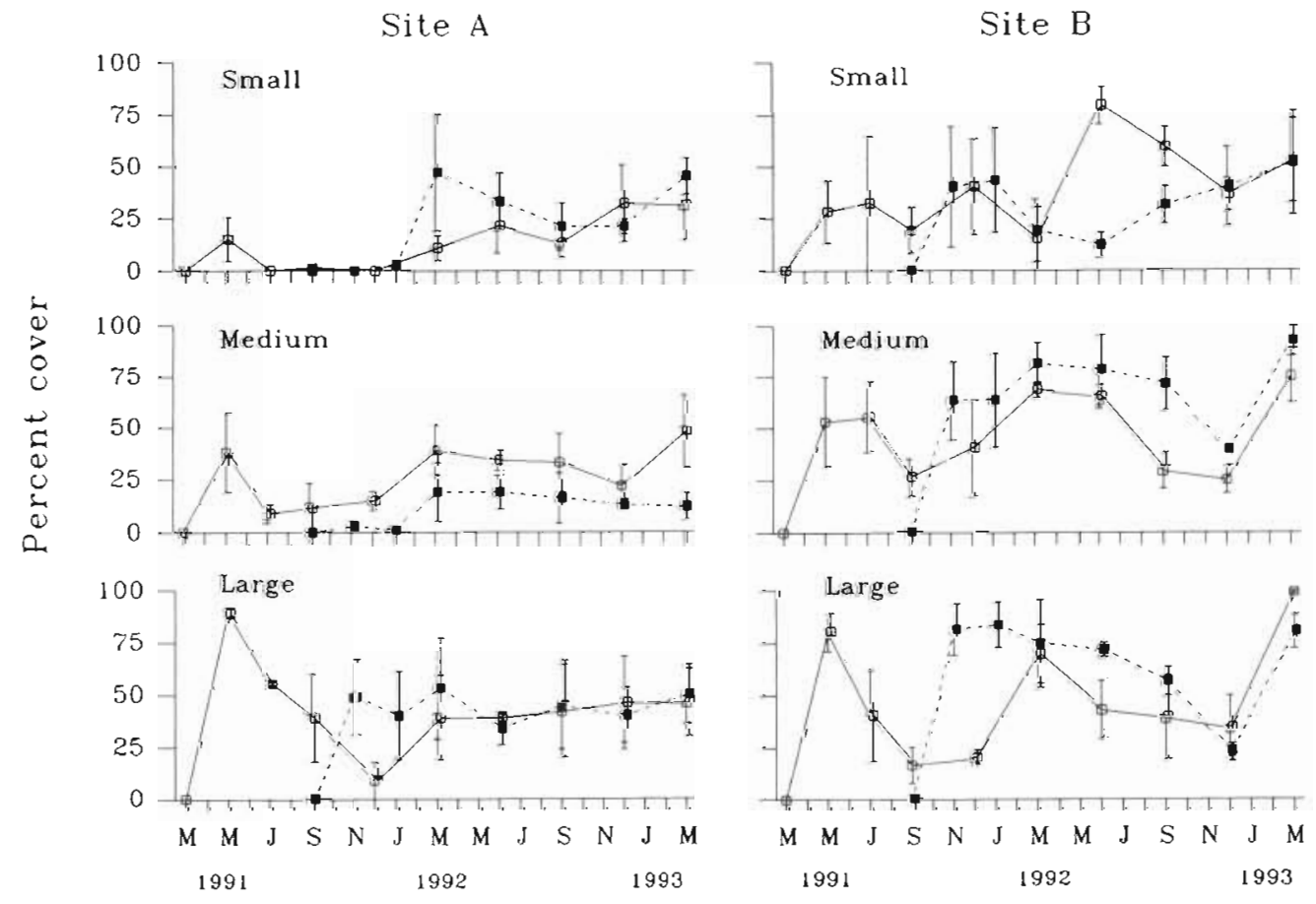

Fig. 3. Effects of size, time of formation and location of patch on filamentous algae. Values are mean $( \pm S E, n=3)$ untransformed percent covers. Symbols as in Fig. 2 

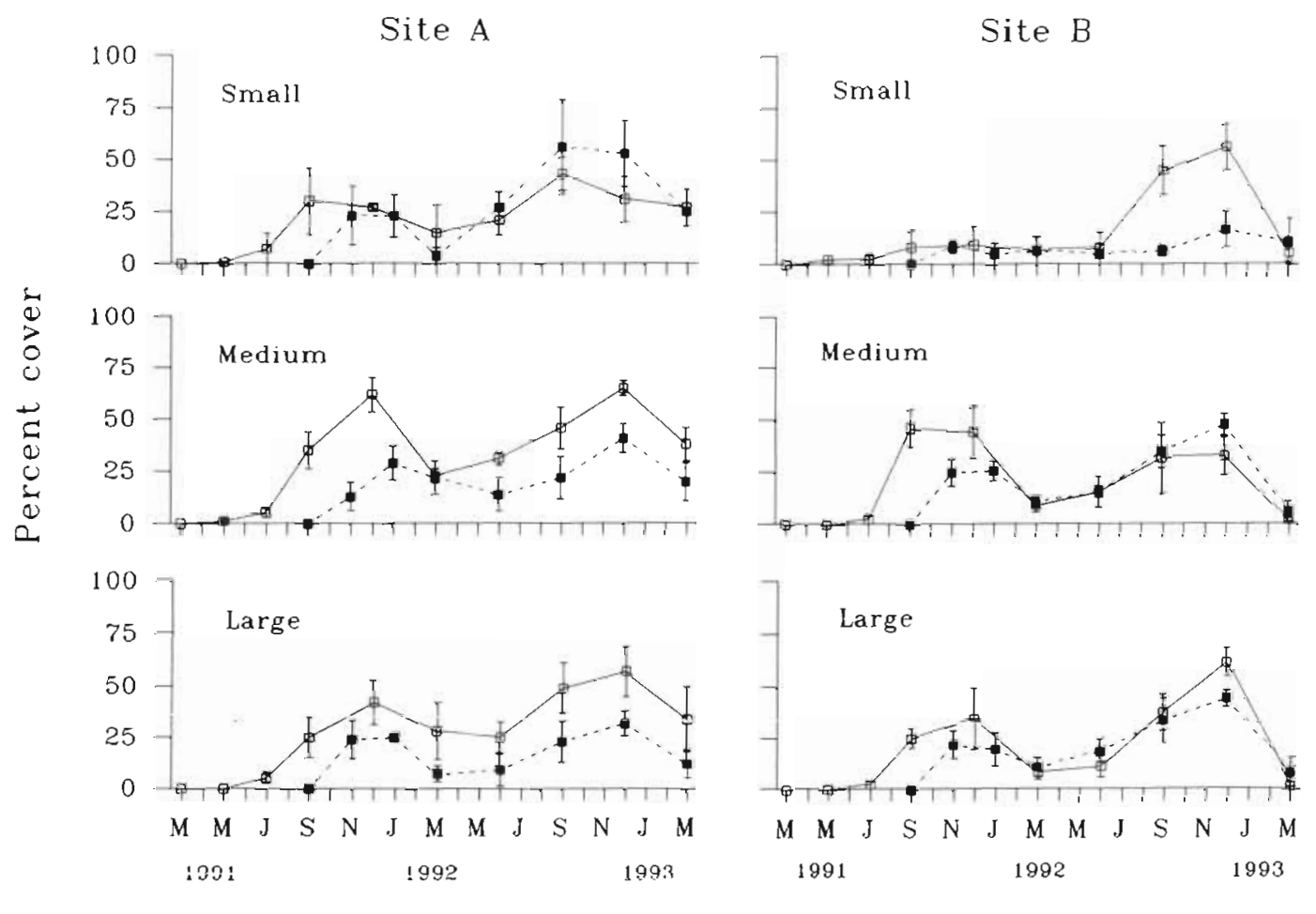

Fig. 4. Effects of size, time of formation and location of patch on geniculate coralline algae. Values are mean $( \pm S E$, $n=3)$ untransformed percent covers. Symbols as in Fig. 2
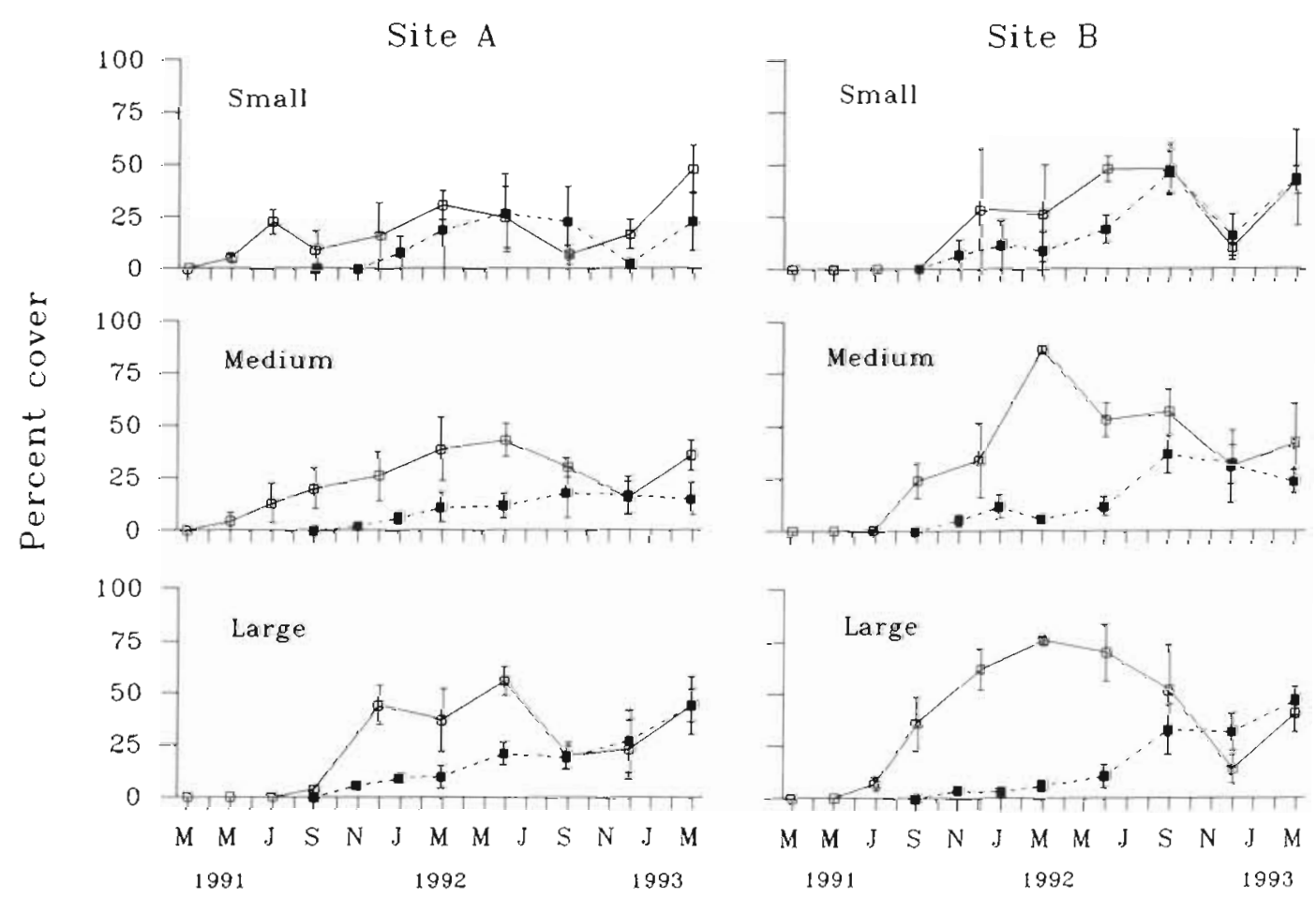

Fig. 5. Effects of size, time of formation and location of patch on coarsely branched algae. Values are mean $( \pm \mathrm{SE}, \mathrm{n}=3)$ untransformed percent covers. Symbols as in Fig. 2 
experiment (only the large and medium gaps were included in these analyses; see also Table 1). Colonisation by filamentous algae was also spatially variable. They were more abundant at Site B than at Site A (Fig. 3) and such differences were significant $(p<0.01)$ after 12 mo of recovery. A significant interaction between site and time of formation of patch occurred after 18 mo from start (Table 1). At that time, algal cover was greater in plots cleared in September than in those cleared in March, but such differences were evident only at Site B.

Both size and time of formation of patches had some effects on the colonisation of geniculate coralline algae (Fig. 4). The abundance of these species was lower in the small plots than in the other treatments, particularly during the early stages of succession. In contrast, differences among the large and medium gaps were less evident and were not significant after 6,12 and 18 mo from the start of the experiment (Table 1). In general, algal abundance was greater in September than in March independently of the period of the year when the experiment was initiated. A significant difference for large and small quadrats was detected after 18 mo of recovery (Table 1). This pattern was a consequence of marked seasonality by the geniculate coralline algae (see also Fig. 1). These species, in fact, peaked in abundance from September to December in treatment and control plots (Figs. $1 \& 4$ ). Seasonal effects, however, were not consistent between sites after 12 mo of succession. At that time, differences among patches cleared in March and September were pronounced at Site B, but did not occur at Site A. This resulted in a significant $(p<0.05)$ interaction among factors. Finally, a trend toward a greater abundance of articulated corallines at Site A was evident by the end of the study, although differences among sites were not significant after 6,12 and 18 mo of recovery.

The patterns of colonisation exhibited by the coarsely branched algae are shown in Fig. 5. The abundance of these species was low early in succession. It increased considerably after 9 to 12 mo from the start of the experiment to decline again in December 1992. Seasonal trends in control areas (Fig. 1) explained the increase in abundance observed in March 1993 in almost all the experimental areas (Fig. 5). In general the cover of the coarsely branched algae was lower in the small gaps than in the medium and large clearings, but differences also occurred among the latter treatments. After $12 \mathrm{mo}$ of succession, the medium plots supported higher abundances of coarsely branched algae than the large ones, but only in clearings initiated in March (Fig. 5). This resulted in a highly significant interaction $(p<0.01)$ among size and time of formation of patches. The pattern disappeared 3 mo later, with greater algal abundance found in large clearings independently from the time at which the experiment was initiated (Table 1). After 6 mo of recovery, both the medium and large gaps cleared in March supported greater abundances of coarsely branched algae than those produced in September, but only at Site B. This resulted in a significant interaction $(p<0.05)$ between time of clearing and site. Differences between sites, however, decreased as succession proceeded; the effect of time of formation of patches was significant after 15 mo from start, but there was no interaction with the factor site (Table 1). This, in turn, was highly significant $(p<$ $0.01)$ for patches 12 mo old. Also the recovery of small plots was spatially variable. The abundance of coarsely branched algae was greater at Site A than at Site $B$ during the early stages of colonisation (the pattern was more evident in plots cleared in March), while the reverse occurred from June to September 1992 (Fig. 5).

\section{DISCUSSION}

The results indicate that colonisation by macroalgae was a variable process in the low-shore habitat. It is worth noting, however, that the power of tests on the effects of size and time of formation of patches and their interaction probably was low in this study. As noted by McKone (1993), until treatments are replicated in few sites, there is little statistical power to make inferences concerning treatment effects themselves. Nevertheless, all main factors and some interactions affected recovery of patches. In addition, results also indicate that patterns were specific for each algal morphological group and were not consistent along the successional sequence.

In general, medium and large clearings supported greater covers of macroalgae than did small areas. Inspection of graphs suggest that such effects decreased with time. A number of factors could account for these patterns. Small gaps are expected to support greater covers of organisms than large ones when colonisation by vegetative growth is important (Sousa 1985, Farrell 1989). Conversely, if vegetative propagation is unimportant and recovery depends primarily on settlement, large clearings will be favored (Keough 1984, Sousa 1984, 1985). Lateral growth appeared of little relevance as a mechanism of patch recovery at our study sites. Neither the filamentous algae nor the articulated corallines were affected by position within the large gaps when the edge and the central zones of those areas were compared (Benedetti-Cecchi unpubl. data). Hence, the most probable mechanisms of colonisation were recruitment from spores for the former organisms and, in addition 
to this, regeneration from persistent basal crusts for the latter (Benedetti-Cecchi pers. obs.). According to Sousa (1985), the greater abundance of algae in large plots could be explained as a consequence of greater area alone: large clearings are expected to sample a greater proportion of the propagules and spores available in the water column than are small areas. In addition, factors reducing algal recruitment and growth could also have operated in small plots. In some instances, competitive interactions among species recently settled in a patch and the organisms surrounding that patch have been invoked as mechanisms limiting colonisation of small areas (Connell \& Keough 1985, Sousa 1985). Shading and sweeping by the canopy may exert a strong negative impact on survival of newly-settled individuals in algal communities (Dayton 1975, Sousa 1979, Velimirov \& Griffiths 1979, Reed \& Foster 1984, Kennelly 1989). Such effects, however, appeared unimportant in the assemblaye considered here, where all the component species had a small size and did not form a canopy.

As already suggested, algal recovery in small areas was not completely inhibited, but only delaycd in comparison with colonisation of large clearings. Hence, whatever the mechanism(s) accounting for the pattern, its (their) effect generally decreased as succession proceeded. Possibly, the algal spores and propagules accumulated during the first months of colonisation in the small patches persisted as a 'bank of microscopic forms' (Chapman 1986), suppressing or reducing their development because of unfavourable environmental conditions. The recent literature provides some evidence supporting the existence of such 'banks' in the marine benthos (Santelices 1990, Hoffmann \& Santelices 1991).

In contrast to the patterns discussed above, differences among medium and large areas were found after 15 mo of recovery for the coarsely branched algae (Table 1). This is a notable exception, indicating that generalizations about changes in the effects of size of patches with time are not legitimate when clearings of very different areal extent are considered. The results reported here also indicate that generalizations are not possible because the effects due to the size of gaps may change in direction with time. For example, after 12 mo of recovery the medium gaps cleared in March supported greater covers of coarsely branched algae then the large areas produced at the same time (see 'Results'). At present we do not have any solid explanation for these patterns and further research is necessary to clarify the causes of this variability.

The time at which the study was initiated greatly affected the abundance of macroalgae in the experimental areas (see also Hawkins 1981). Significant effects involving the factor time were detected on sev- eral occasions. It is worth noting, however, that differences in algal abundance among patches of similar age but produced at different times did not necessarily reflect differences in initial recruitment. This was true for young patches, but significant temporal effects occurring late in succession should be interpreted simply as seasonal trends. In other words, initial differences in algal recruitment, reflecting differences in propagule availability and algal growth at the time of treatment initiation, were not maintained through time as the successional trajectories observed at each site converged towards similar points (see Figs. $3 \& 4$ ).

Patterns of colonisation were also highly variable between sites. In general, the filamentous and coarsely branched algae were more abundant at Site B than at Site A. A number of studies have shown that the recruitment and distribution of marine benthic organisms may vary greatly in space, even in environments with apparently the same abiotic conditions (e.g Foster 1990, Schiel 1990, Kennelly \& Underwood 1992). Spatial patterns may be due either to variability in post-settlement growth and mortality of organisms or to differences in the local availability of larvae and propagules (Denley \& Underwood 1979, Hawkins \& Hartnoll 1982, Sousa 1984, 1985, Underwood \& Denley 1984, Caffey 1985, Connell 1985, Gaines \& Roughgarden 1985, Roughgarden et al. 1988, Raimondi 1990 Menge 1991). Sousa (1984), for example, found considerable spatial variation in the recruitment of algae to experimental patches. The percentage cover of several recruiting species was highly correlated with the cover of epizoic conspecific adults within $1 \mathrm{~m}$ from the edges of the experimental areas. These results pointed to the importance of patch location with respect to the distribution of adult organisms: recovery will be influenced mainly by species close to the cleared area, provided that local populations disperse their propagules over short distances (e.g. Dayton 1973, Paine 1979). One of the most obvious differences among the sites considered in this study was the spatial distribution of the dominant assemblages. Although the experimental units were stratified within patches of geniculate corallines and associated species at both locations, these organisms dominated the sublittoral-fringe habitat only at Site B, while space at Site A was occupied mainly by mussels and the brown alga Cystoseira compressa. As a consequence, the local availability of settling propagules and spores could also differ among locations. Filamentous, ephemeral species, however, are known to disperse their offspring over long distances and their recruitment may be uncoupled from within-site reproduction of conspecific adults (Reed et al. 1988, Santelices 1990). Thus, factors other than local production of spores could have affected the spatial distribution of filamentous algae. For example, hydro- 
dynamic factors have been shown to influence the distribution of barnacle larvae in the water column and consequently the spatial distribution of adults on the coast (Gaines \& Roughgarden 1985, Roughgarden et al. 1988, Gaines \& Bertness 1992). Likewise, inshore circulation of water could also have carried more spores of filamentous species to one site than to the other. The points discussed above could also explain the spatial distribution of the coarsely branched algae, although no data are available in the literature on the range of dispersal of the species found in this study.

As for the effects of size and time of formation of clearings, the differences between sites were also not consistent along the successional sequence. Location of patch was more important at mid and late successional stages for the filamentous species and at early and mid stages for the coarsely branched algae. In addition, the articulated corallines were more abundant at Site A by the end of the study (Fig. 4). Probably, these patterns were not only determined by variability in recruitment of species, but also by between-site differences in seasonal fluctuations. Clearly, further research is necessary on these aspects of community structure. Understanding the causes of spatial and temporal variation of benthic organisms is one of the most important issues of marine ecology, not only for the development of ecological theory (Roughgarden et al. 1985) but also for management purposes (Underwood 1991, 1992, Kennelly \& Underwood 1992).

In synthesis, the data presented in this study do not completely support the results obtained from some rocky intertidal communities, where initial differences among treatments became less evident as colonisation proceeded (reviewed in Sousa 1985). Here, patterns of succession always converged in clearings produced in different periods of the year, but not in patches of different size or produced at different sites. In these cases differences among treatments changed but not necessarily decreased with time. Overall, these results suggest caution in contrasting deterministic and nondeterministic views of community dynamics.

Acknowledgements. We thank Profs. S. Bonotto, M. S. Foster and A. J. Underwood, Dr S. J. Hawkins and 2 anonymous referees for helpful comments on the manuscript. This work was supported by a MURST $60 \%$ project to F.C.

\section{LITERATURE CITED}

Benedetti-Cecchi, L. (1993). Perturbazioni naturali ed organizzazione spazio-temporale di due comunità marine bentoniche superficiali del litorale livornese: una analisi sperimentale. Ph.D. thesis, Pisa University

Breitburg, D. L. (1985). Development of a subtidal epibenthic community: factors affecting species composition and the mechanisms of succession. Oecologia 65: 173-184
Butler, A. J (1991). Effect of patch size on communities of sessile invertebrates in Gulf St Vincent, south Australia. J. exp. Mar. Biol. Ecol. 153: 255-280

Caffey, H. M. (1985). Spatial and temporal variation in settlement and recruitment of intertidal barnacles. Ecol. Monogr. 55: 313-332

Chapman, A. R. O. (1986). Population and community ecology of seaweeds. In: Blaxter, J H. S., Southwood, A. J. (eds.) Advances in marine biology, Vol. 23. Academic Press, London, p. 1-161

Connell, J. H. (1985). The consequences of variation in initial settlement vs. post-settlement mortality in rocky intertidal communities. J. exp. mar. Biol. Ecol. 93:11-45

Connell, J. H., Keough, M. J. (1985). Disturbance and patch dynamics of subtidal marine animals on hard substrata. In: Pickett, S. T. A., White, P. S. (eds.) The ecology of natural disturbance and patch dynamics. Academic Press, Orlando, p. 125-151

Dayton, P. K. (1971). Competition, disturbance, and community organization: the provision and subsequent utilization of space in a rocky intertidal community. Ecol. Monogr. 41 : $351-389$

Dayton, P. K. (1973). Dispersion, dispersal, and persistence of the annual intertidal alga, Postelsia palmaeformis Ruprecht. Ecology 54: 433-438

Dayton, P. K. (1975). Experimental evaluation of ecological dominance in a rocky intertidal algal community. Ecol. Monogr. 45: 137-159

Dayton, P. K., Curril, V., Gerrodette, T., Keller, B. D., Rosenthal, R., Tresca, D. V. (1984). Patch dynamics and stability of some California kelp communities. Ecol. Monogr. 54: 253-289

Dayton, P. K., Tegner, M. J., Parnell, P. E., Edwards, P. B. (1992). Temporal and spatial patterns of disturbance and recovery in a kelp forest community. Ecol. Monogr. 62: $421-445$

Denley, E. J., Underwood, A. J. (1979). Experiments on factors influencing settlement, survival and growth of two species of barnacles in New South Wales. J. exp. Mar. Biol. Ecol. 36: $269-293$

Dethier, M. N. (1984). Disturbance and recovery in intertidal pools: maintenance of mosaic patterns. Ecol. Monogr. 54: $99-118$

Farrell, T. M. (1989). Succession in a rocky intertidal community: the importance of disturbance size and position within a disturbed patch. J exp. mar. Biol. Ecol. 128:57-73

Farrell, T. M. (1991). Models and mechanisms of succession: an exámple from a rocky intertidal community. Ecol. Monogr. 61. 95-113

Foster, M. S. (1975). Algal succession in a Macrocystis pyrifera forest. Mar. Biol. 32: 313-329

Foster, M. S. (1990). Organization of macroalgal assemblages in the northeast Pacific: the assumption of homogeneity and the illusion of generality. Hydrobiologia 192: 21-33

Gaines, S. D., Bertness, M. D. (1992). Dispersal of juveniles and variable recruitment in sessile marine species. Nature 360: $579-580$

Gaines, S. D., Roughgarden, J. (1985). Larval settlement rate: a leading determinant of structure in an ecological community of the marine intertidal zone. Proc. natl Acad. Sci. U.S.A. 82 : $3707-3711$

Hawkins, S. J. (1981). The influence of season and barnacles on the algal colonization of Patella vulgata exclusion areas. J. mar. biol. Ass. U.K. 61: 1-15

Hawkins, S. J., Hartnol, R. G. (1982). Settlement patterns of Semibalanus balanoides (L.) on the Isle of Man (1977-1981). J. exp. mar. Biol. Ecol. 62: 271-283 
Hoffmann, A. J., Santelices, B. (1991). Banks of algal microscopic forms: hypotheses on their functioning and comparisons with seed banks. Mar. Ecol. Prog. Ser. 79: 185-194

Kay, A. M., Keough, J. J. (1981). Occupation of patches in the epifaunal communities on pier pilings and the bivalve Pinna bicolor at Edithburgh, South Australia. Oecologia 48: $123-130$

Kennelly, S. J. (1989). Effects of kelp canopies on understorey species due to shade and scour. Mar. Ecol. Prog. Ser. 50: 215-224

Kennelly, S. J., Underwood, A. J. (1992). Fluctuations in the distributions and abundances of species in sublittoral kelp forests in New South Wales. Aust. J. Ecol. 17: 367-382

Keough, M. J. (1984). Effects of patch size on the abundance of sessile marine invertebrates. Ecology $65: 423-437$

Konar, B., Foster, M. S. (1992). Distribution and recruitment of subtidal geniculate coralline algae. J. Phycol. 28: 273-280

Likens, G. E. (1992). The ecosystem approach: its use and abuse. In: Kinne, O. (ed.) Excellence in ecology. Ecology Institute, Oldendorf/Luhe

Littler, M. M., Kauker, B. J. (1984). Heterotrichy and survival strategies in the red alga Corallina officinalis L. Botanica mar. $27: 37-44$

Littler, M. M., Littler, D. S. (1980). The evolution of thallus form and survival strategies in benthic marine macroalgae. Am. Nat. 116: 25-44

McKone, M. J. (1993). Statistical analysis of experiments conducted at multiple sites. Oikos 67: $184-186$

Menge, B. A. (1991). Relative importance of recruitment and other causes of variation in rocky intertidal community structure. J. exp. mar. Biol. Ecol. 146: 69-100

Paine, R. T. (1979). Disaster, catastrophe and local persistence of the sea palm Postelsia palmaeformis. Science 205: $685-687$

Paine, R. T., Levin, S. A. (1981). Intertidal landscapes: disturbance and the dynamics of pattern. Ecol. Monogr. 51: $145-178$

Pickett, S. T. A., White, P. S. (1985). Natural disturbance and patch dynamics: a synthesis. In: Pickett, S. T. A., White, P. S. (eds.) The ecology of natural disturbance and patch dynamics. Academic Press, Orlando, p. 371-384

Raimondi, P. T. (1990). Patterns, mechanisms, consequences of variability in settlement and recruitment of an intertidal barnacle. Ecol. Monogr. 60: 283-309

Reed, D. C., Foster, M. S. (1984). The effects of canopy shading on algal recruitment and growth in a giant kelp forest. Ecology 65: $937-948$

Reed, D. C., Laur, D. R., Ebeling, A. W. (1988). Variation in algal dispersal and recruitment: the importance of episodic events. Ecol. Monogr. 58: 321-335

Roughgarden, J., Gaines, S., Possingham, H. (1988). Recruitment dynamics in complex life cycles. Science 241 : $1460-1466$

This article was submitted to the editor
Roughgarden, J., Iwasa, Y., Baxter, C. (1985). Demographic theory for an open marine population with space-limited recruitment. Ecology 66: 54-67

Santelices, B. (1990). Patterns of reproduction, dispersal and recruitment in seaweeds. Oceanogr. mar. Biol. A. Rev. 28: $177-276$

SAS Institute, Inc. (1985). SAS user's guide: statistics. SAS Institute, Inc., Cary, NC

Schiel, D. R. (1990). Macroalgal assemblages in New Zealand: structure, interactions and demography. Hydrobiologia 192: $59-76$

Sousa, W. P. (1979). Experimental investigations of disturbance and ecological succession in a rocky intertidal community. Ecol. Monogr. 49: 227-254

Sousa, W. P. (1984). Intertidal mosaics: patch size, propagule availability, and spatially variable patterns of succession. Ecology 65: 1918-1935

Sousa, W. P. (1985). Disturbance and patch dynamics on rocky intertidal shores. In: Pickett, S. T. A., White, P. S. (eds.) The ecology of natural disturbance and patch dynamics. Academic Press, Orlando, p. 101-124

Steneck, R. S., Watling, L. (1982). Feeding capabilities and limitation of herbivorous molluscs: a functional group approach. Mar. Biol. 68: 299-319

Turner, T. (1983a). Complexity of early and middle successional stages in a rocky intertidal surfgrass community. Oecologia 60: 56-65

Tumer, T. (1983b). Facilitation as a successional mechanism in a rocky intertidal community. Am. Nat. 121: 729-738

Underwood, A. J. (1981). Techniques of analysis of variance in experimental marine biology and ecology. Oceanogr. mar. Biol. A. Rev. 19: 513-605

Underwood, A. J. (1991). Beyond BACI: experimental designs for detecting human environmental impacts on temporal variations in natural populations. Aust. J. mar. Freshwat. Res. 42 569-587

Underwood, A. J. (1992). Beyond BACI: the detection of environmental impacts on populations in the real, but variable, world. J. exp. mar. Biol. Ecol. 161: 145-178

Underwood, A. J., Denley, E. J. (1984). Paradigms, explanations and generalizations in models for the structure of intertidal communities on rocky shores. In: Strong, D. R., Simberloff, D., Abele, L. G., Thistle, A. B. (eds.) Ecological communities: conceptual issues and the evidence. Princeton University Press, Princeton, p. 151-180

Velimirov, B., Griffiths, C. L. (1979). Wave-induced kelp movement and its importance for community structure. Botanica mar. 22: 169-172

Winer, B. J. (1971). Statistical principles in experimental designs, 2nd edn. McGraw-Hill Kogakusha, Tokyo

Wootton, J. T. (1993). Size-dependent competition: effects on the dynamics vs. the end point of mussel bed succession. Ecology 74: 195-206

Manuscript first received: October 12, 1993

Revised version accepted: March 24, 1994 